\title{
Range Free Localization Techniques for Randomly Deployed WSN-A Survey
}

\author{
Ravneet Kaur ${ }^{1}$ and Jyoteesh Malhotra ${ }^{2}$ \\ ${ }^{1,2}$ ECE Department, Guru Nanak Dev University, Regional Campus, Jalandhar, \\ Punjab, India \\ ravneetkaur4141@gmail.com ${ }^{1}$,jyoteesh@gmail.com ${ }^{2}$
}

\begin{abstract}
Recent advancements in MEMSs technology, VLSI and wireless private area networks have contributed in developing enormous interest in wireless sensor networks by both academia and research community. WSN is formed by large number of small, cheap and low energy sensors that work together in monitoring region. These sensors sense, collect and forward data within the network through wireless medium. WSN find its application in many areas such as object tracking, disaster relief and smart environments etc. Most of these applications need location awareness of sensor nodes to estimate the place of origin of events. The task of determining physical coordinates of sensor nodes within the network is known as localization. Localization has always remained a challenge in successful implementation of WSN and so, it is a hotspot of research. Localization techniques are broadly categorized as Range based techniques and Range-free techniques based on their dependency on range measurements. Because of constraints on cost, energy, computation complexity and infrastructure requirements, range free localization techniques are given importance in recent research works. Considering the latest trends in localization, a thorough analysis for major range free techniques is done in this paper and accordingly their pros and cons are highlighted. As the existing range free techniques are not fully efficient so, open issues are also raised to give directions to future research.
\end{abstract}

Keywords: Localization, Range-free techniques, Localization accuracy

\section{Introduction}

Wireless sensor networks (WSNs) [16] have gained worldwide attention in recent years. Latest developments in MEMSs technology and wireless communication have further contributed in the use of large scale wirelessly connected tiny sensors in variety of application areas such as intrusion detection and identification, health, habitat and environment monitoring, military target tracking and surveillance[2].

A WSN is formed by large number of sensors working together to monitor a deployed region for physical characteristics and environment conditions such as temperature, sound, vibration, pressure, motion, and pollutants. Sensors play a vital role in WSN by testing, sensing, gathering, measuring and then transferring the data wirelessly to the base station for the further processing.

A wireless sensor network is widely applied in many location dependent applications such as monitoring the pipelines of oil, water and gas. These pipelines have high risk and high cost due to their long length and also have difficult access conditions. These conditions challenge their management and therefore, pipelines need continuous checking to avoid leakages. Leakages can occur due to natural hazards (earthquakes and landslides), corrosion, wear and tear with time or even intentional damage to the structure. So, it becomes very important to detect the leakages at the very starting. This can be easily done by deploying different sensors like pressure sensors, $\mathrm{pH}$ sensors, temperature sensors and seismic sensors within the pipeline to keep check on the leakages. But the 
information sensed by the sensors will be of no use if the location of leakage point is not discovered. Therefore, knowing the spatial relationship between origin of the event and sensors themselves is an important task. This process of determining physical coordinates of sensors deployed in WSN is known as localization.

However, GPS is well known location sensing system but, some constraints of WSN make it unacceptable in certain environments. Firstly, GPS is not accessible in all environments (indoor and dense urban or forest area) because of line of sight requirement of GPS. Secondly, use of GPS involves resource costs and installation costs that are unacceptable in the network of resource constrained tiny and cheap sensor nodes. Thirdly, GPS estimates location within $10 \mathrm{~m}$ for $90 \%$ of measurements, which is obviously not accepted in WSN applications. Fourthly, high power consumption by GPS based location system makes it impractical in very less power consuming sensor network deployed in monitoring region. So, localization in WSN is done using set of techniques that allow a sensor to calculate its own position based on information gathered from the sensor's environment. WSN localization techniques are broadly categorized into Range based and Range Free Techniques based on their dependency on range measurements.

Range based localization techniques use various range measurement methods[19] such as Received Signal Strength Indicator(RSSI)[18], angle of Arrival(AOA),Time of Arrival(TOA) [5] and Time Difference Of Arrival(TDOA) to measure the distance between anchor nodes and unknown nodes(locating the nodes). On contrary, Range free localization techniques [8] don't use any ranging methods instead, they just use the connectivity information between sensors i.e. "who comes in the communication range of whom' concept is used, to estimate the location of sensor nodes with somewhat lesser accuracy. But most of the applications of WSN just need the coarse estimates of location of sensor nodes. Also, range free techniques overpower the range based techniques in terms of lesser power consumption, low cost, no extra hardware, less installation and computational complexity. So, these features of range free techniques have attracted a lot of research efforts in recent years.

In this paper, latest trends of range free localization techniques are focused and related literature has been studied in next section followed by its summary and the related issues for future research. Section 5 raises the open issues for driving the attention of upcoming researchers in this field. Finally we conclude the paper in Section 6.

\section{Background}

In WSN, GPS is employed on only a fraction of sensor nodes(called anchor nodes or beacon nodes) and other sensor nodes without location information(unknown nodes) calculate their position using anchor nodes. This process is thus called node self localization or cooperative localization.

Range free localization techniques estimate node locations based on connectivity information to anchor nodes and are satisfactorily accurate. For many applications of large scale networks, a coarse estimate of sensor's locations is usually sufficient.

So, Range free techniques prove to be the best option in such networks.

\subsection{Important Terms}

There are many concepts used while implementing range free localization in WSN such as:

2.1.1. Centralized Algorithm: A centralized algorithm uses a central processing unit(or base station) to which all sensors pass the connectivity information and then resultant final locations are passed from central unit to the respective nodes. The convenience of centralized localization is that it eliminates the need of computation at each node but 
drawback lies in the computation complexity at base station and cost involved in moving data to and from central base station [5].

2.1.2. Distributed Algorithm: In distributed algorithm, all the positioning calculations are done at the sensor node level and the nodes communicate with each other to get their position in the network. It is much simpler than centralized and mainly supports scalability of WSN [5].

2.1.3. Trilateration: Trilateration is a positioning technique that uses geometry of circles and triangles to determine the coordinates of unknown nodes [20]. Measured distances between a number of anchor nodes and the unknown node itself indicates that the sensor must lie along the circumference of a circle centered at the anchor's position with a radius equal to the sensor-anchor distance. So, for unique position of sensor node in $2 \mathrm{~d}$ it requires at least three non-collinear anchor nodes i.e. intersection of these three circles.

2.1.4. Triangulation: Triangulation uses the geometric properties of triangles, laws of sine's and cosines to estimate location of sensor nodes [2].Specifically, this mechanism relies on the gathering of angle measurements. In two-dimensional space, at least two bearing lines and the locations of the anchor nodes or the distance between them are needed to determine the unknown node's position.

\subsection{Performance Parameters}

Range-free (or proximity based) localization techniques are compared on the basis of some parameters that are explained below:

2.2.1. Cost: WSN consists of inexpensive sensors. So, locating these sensor nodes should be economical for its widespread use.

2.2.2. Accuracy Rate: Position of nodes is required in many applications of WSN. So accuracy in location of sensors should be higher for maintaining reliability on the network.

2.2.3. Energy Consumption: Small sensor nodes forming the network consume very low energy. So, localization of sensor nodes should be energy efficient task.

2.2.4. Hardware Requirement: Extra hardware increases cost and complexity of network. So, extra hardware should be avoided in the process of localization.

2.2.5. Robustness: Technique should be tolerant to communication problem as well as errors in positioning.

2.2.6. Scalability: Techniques should be extendible to large scale networks.

2.2.7. Computational Complexity: Minimum complexity should be involved in computing position of nodes to reduce localization errors.

2.2.8. Node density: A good Localization technique performs well in limited node density as well as in large node density.

\section{Literature Survey}

The concept of range free localization technique was first implemented in year 2000 with the introduction of Centroid Technique. Since then, range free localization 
techniques have evolved with better solutions to available techniques depending on the areas of their application. Here, 4 major range free techniques and the important works based on these techniques are reported and their results are reviewed.

Range Free Localization is implemented using 4 Major Techniques:

(i) Centroid Technique

(ii) DV-HOP Technique

(iii) APIT Technique

(iv) MDS Technique

In 2000, Bulusu et al. proposed Centroid Algorithm(CA)[14]. It was the most basic scheme that used anchor nodes, containing location information (Xi, Yi) to estimate unknown node position. Each anchor node broadcasts its location to its neighbor nodes and when the numbers of beacons from anchors exceed a certain threshold, following Centroid formula [14] was used to compute the unknown node location:

$$
X_{e s t}, Y_{e s t}=\frac{1}{n}\left(\sum_{i=1}^{n} X_{i}, \sum_{i=1}^{n} Y_{i}\right)
$$

where $X_{\text {est }}$ and $Y_{\text {est }}$ are estimated coordinates of unknown node, $n$ is the number of anchor nodes $\mathrm{A}_{\mathrm{i}}$ and $\left(\mathrm{X}_{\mathrm{i}}, \mathrm{Y}_{\mathrm{i}}\right)$ are co-ordinates of anchor nodes.

Although centroid technique gained attention due to its simplicity, low cost and ease of implementation but localization accuracy was vulnerable to be affected by the number of anchor nodes and node orientation in the network. So, many improvements were done to increase its accuracy.

Recently in 2011, X. Su etc. presented an improved and relatively simple centroid algorithm [6]. Weighted location correction vector was used to get best possible minimal difference between the calculated distances and measured distances that expectedly enhanced the accuracy of measured distances. Secondly, the use of intelligent Particle Swarm Optimization (PSO) [17] fastened the convergence to get the better results. These improvements decreased the localization error rapidly. But, calculations involved to get good accuracy were larger and took longer time.

In 2001, D. Niculescu and B.Nath, proposed a new Range free localization technique i.e. DV-HOP localization algorithm [4,9] that used distance vector method for position estimation. Firstly, all the unknown nodes got minimum hop count from the anchor nodes. Then distance between them and anchor nodes were calculated by multiplying minimum hop count value and average size of one hop. Finally, the location of sensor was estimated using Trilateration method [20].It showed better results than Centroid algorithm and also covered much larger area than CA but it suffered from large location error due to uncertainty in the calculation of average hop size.

So, many improvements were suggested to increase the positioning accuracy of DVHOP. One of the significant works was done by Dai Chen, Wei Wang, and Yong Zhou in 2010[1]. They introduced three improved methods to settle the large location error of the classic DV -Hop localization algorithm. First, the average hop size was calculated by using least square method [5]. Second, the distance between unknown nodes and anchor nodes was calculated by considering average hop size of different anchor nodes as compared to classical DV-HOP where unknown nodes save the first received average hop size value. Third, the initial location of unknown nodes was calculated using Multilateration method repeatedly, then the average of them gave the final location. The simulation results showed that these improvements greatly enhanced the localization accuracy of unknown nodes but at the cost of increased computational overhead.

Then in 2013 J.Xiang et. al., proposed a new improved DV-HOP Algorithm[13] to put his significant contribution to embellish the results of DV-HOP. Localization error in classical DV-HOP mainly occurred while estimating the average hop size. So, 
improvement was done in calculating best average hop size using Iterative Computation. Simulation results showed that proposed iteration DV-HOP Algorithm suffered lesser localization error than classical DV-HOP algorithm when various values of number of anchor nodes, total number of nodes and radio ranges of sensors were considered.

In DV-Hop algorithm, error at initial steps may propagate throughout the network during following steps. So, even a small estimation error can cause large localization error during calculation of final coordinates of unknown nodes. Although, by increasing the number of anchors, accuracy can increase but it will lead to increased cost of the network. So, Tian He, et al followed an area based approach and presented an approximate point-in-triangulation test (APIT), a novel range free localization algorithm [7]. Distance information between the nodes was not required thus, it eliminated the localization error involved in considering average distance between the nodes. It was based on the principle of dividing the whole network into triangular regions whose vertices were formed by connecting all the possible set of three neighboring anchor nodes. The unknown node received the information from its neighboring nodes that helps to determine whether it is inside/outside the triangle formed by anchor nodes and the final centric location of overlapping regions was considered as estimated location. This algorithm showed best performance in random node placement and required low hardware, that made it novel scheme. However, the localization accuracy in the APIT method was affected by a node's presence whether it is within the triangular regions or not.

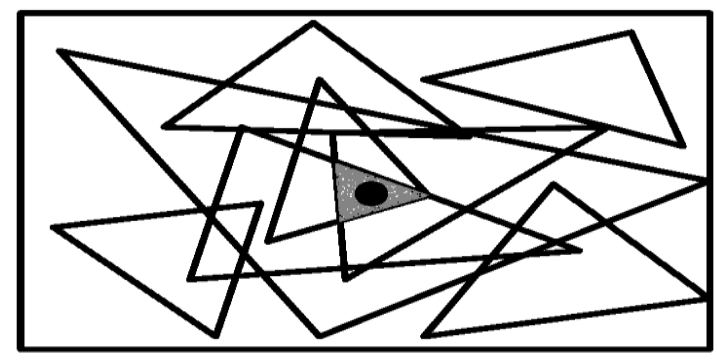

Figure 1. APIT Technique [7]

Further J.Z. Wang and Hongxu Jin worked for increasing the efficiency of APIT and thus introduced Improved APIT [3] in 2009 that upgraded the average accuracy of algorithm as compared to original APIT. It aimed on eliminating the edge effect [7] that was the main reason of position measurement error. So, backtracking and area test were used to reduce the percentage of error occurrence. But only sufficient node density could give good results and additional memory was also required for storing data of position estimation.

Then in 2014,S. M. Hosseinirad modified APIT localization algorithm by Segmenting the application area into four non overlapping and four overlapping sub regions[15]. This modification remarkably reduced computational load and useless anchor selection. Also suitable triangles were selected with appropriate distance between the anchors that eliminated the PIT errors due to edge effect. Modified APIT showed better outcomes in terms of average error and computational time involved for all sizes of WSN with random and grid deployments. Although, for more accurate location estimation, minimum 5 anchors were still required in each of the sub regions.

APIT produced much finer results than DV-HOP and Centroid Algorithm but for certain scenarios only. So, Y. Shang, W. Ruml, Y. Zhang and M.P.J. Fromherz look forward for a better solution to the available proposals. They proposed a centralized range free localization method for sensor networks termed as MDS-MAP [11] that used just the basic connectivity information of the nodes deployed in the network. This localization 
scheme was based on multidimensional scaling (MDS). Firstly, this scheme made rough estimates of the distances between the shortest path pair of nodes. Then MDS was implemented that yielded best suited results for estimated pair wise distances by forming a relative map of location of nodes and finally relative map was transformed using linear transformations (scaling, rotation and reflection) to get the true location of unknown nodes. Capability of forming relative maps when there were no anchor nodes was the main advantage of this algorithm. Only 3 anchors were required to get the absolute coordinates of sensor nodes in the network.

Like other available schemes MDS-MAP was also not able to perform well in irregular networks. So, Shang et.al improved his algorithm and labeled it as MDS-MAP (P) [12] that performed good in both uniform as well as irregular networks. It was executed in a distributed fashion. The main idea was to use MDS technique to build a local map of relative coordinates at each node(that consisted of only the immediate neighbors) and then merge these patches of relative maps together to form a global map of absolute coordinates of all sensor nodes. A drawback of MDS MAP (P) was its complex step of merging local maps.

In 2011, F. Doremami et. al., proposed a new scalable, iterative and distributed MDS algorithm [10]. It estimated the distance within the radio range of sensors by using fuzzy weighted cost function that weighed the more accurate measurements more heavily. With increasing iterations, each sensor updated its position estimate by taking initial estimates from neighboring nodes and considering the new position estimate with minimum corresponding local cost function. This algorithm has reduced complexity, convergence time and communication cost involved in localization.

\section{Evaluation of Range Free Localization Techniques}

Above mentioned Range free localization techniques have their own merits and demerits. Each basic technique has been improved many times by different researchers to achieve the superior performance on the basis of localization accuracy, reduced cost and computational complexity. But still, advancements in these techniques are required to achieve the finest results in terms of accuracy of localization. Table below summarizes the most popular range free localization techniques by extracting their pros and cons from above literature review.

Table 1. Evaluation of Range Free Localization Techniques

\begin{tabular}{|c|c|c|c|c|}
\hline S.No. & TITLE(Author) & Description & Pros & Cons \\
\hline 1. & $\begin{array}{l}\text { GPS-less low-cost } \\
\text { outdoor localization for } \\
\text { very small devices- N. } \\
\text { Bulusu, John } \\
\text { Heidemann and } \\
\text { D.Estrin }\end{array}$ & $\begin{array}{l}\text { Centroid Algorithm } \\
\text { introduced. }\end{array}$ & $\begin{array}{ll}\text { - Simple } & \text { to } \\
\text { design } & \\
\text { - Easy } & \text { to } \\
\text { implement } & \end{array}$ & $\begin{array}{l}\text { - High node } \\
\text { density required } \\
\text { for better accuracy } \\
\text { rate } \\
\text { - Error due to } \\
\text { node orientation }\end{array}$ \\
\hline 2. & $\begin{array}{lr}\text { Improved } & \text { Centroid } \\
\text { Algorithm Localization } \\
\text { for WSN Based on } \\
\text { Particle } & \text { Swarm } \\
\text { Optimization- } & \text { Xiaoqin } \\
\text { Su and Zhaoming Lei }\end{array}$ & $\begin{array}{l}\text { - Weighted } \\
\text { location } \\
\text { correction vector } \\
\text { introduced } \\
\text { - Particle Swarm } \\
\text { Optimisation used }\end{array}$ & $\begin{array}{l}\text { - Enhancement of } \\
\text { position accuracy } \\
\text { - PSO fastened } \\
\text { the convergence }\end{array}$ & $\begin{array}{l}\text { - Large } \\
\text { Computational } \\
\text { overhead involved } \\
\text { - Calculations } \\
\text { took longer time }\end{array}$ \\
\hline 3. & $\begin{array}{l}\text { DV based positioning in } \\
\text { Ad Hoc Networks- } \\
\text { Dragos Niculescu and } \\
\text { Badri Nath }\end{array}$ & $\begin{array}{l}\text { DV-Hop Algorithm } \\
\text { introduced }\end{array}$ & $\begin{array}{l}\text { - Give absolute } \\
\text { positioning in } \\
\text { global coordinate } \\
\text { system of GPS } \\
\text { - Able to cover } \\
\text { the whole network }\end{array}$ & $\begin{array}{l}\text { - Large } \\
\text { localization error } \\
\text { - Inappropriate } \\
\text { results in non } \\
\text { uniform networks }\end{array}$ \\
\hline
\end{tabular}




\begin{tabular}{|c|c|c|c|c|}
\hline & & & $\begin{array}{l}\text { due to distributed } \\
\text { nature }\end{array}$ & \\
\hline 4. & $\begin{array}{l}\text { An Improved DV-Hop } \\
\text { localization algorithm } \\
\text { in Wireless Sensor } \\
\text { Networks- Dai Chen, } \\
\text { Wei Wang and Yong } \\
\text { Zhou }\end{array}$ & $\begin{array}{l}\text { - Average hop size } \\
\text { calculated using } \\
\text { least square } \\
\text { method } \\
\text { - Refinement in } \\
\text { average hop size } \\
\text { by considering } \\
\text { different anchors } \\
\text { - Used Repeated } \\
\text { multilateration }\end{array}$ & $\begin{array}{l}\text { - Enhancement of } \\
\text { localization } \\
\text { accuracy } \\
\text { - No need of } \\
\text { communication } \\
\text { resources and } \\
\text { accessional } \\
\text { localization } \\
\text { devices }\end{array}$ & $\begin{array}{l}\text { - Increased } \\
\text { computational } \\
\text { overhead }\end{array}$ \\
\hline 5. & $\begin{array}{l}\text { An Improved DV-hop } \\
\text { Algorithm based on } \\
\text { Iterative Computation } \\
\text { for } \\
\text { Wireless } \\
\text { Network Localization- } \\
\text { Jun Xiang and Wei Wei } \\
\text { Tan }\end{array}$ & $\begin{array}{l}\text { Iteration cycles } \\
\text { used to correct the } \\
\text { error }\end{array}$ & $\begin{array}{l}\text { - Better accuracy } \\
\text { without } \\
\text { increasing } \\
\text { hardware cost }\end{array}$ & $\begin{array}{l}\text { - Irregular pattern } \\
\text { of network can } \\
\text { lead to certain } \\
\text { errors } \\
\text { localization }\end{array}$ \\
\hline 6. & $\begin{array}{l}\text { Range-free localization } \\
\text { schemes for large scale } \\
\text { sensor networks- T.He, } \\
\text { C. Huang, B.M. Blum, } \\
\text { J.A. Stankovic, and T. } \\
\text { Abdelzaher }\end{array}$ & $\begin{array}{l}\text { Approximate } \text { Point } \\
\text { in Triangulation } \\
\text { (APIT) method } \\
\text { proposed. }\end{array}$ & $\begin{array}{l}\text { - Performs best in } \\
\text { irregular radio } \\
\text { pattern } \\
\text { - Good accuracy } \\
\text { in random node } \\
\text { placement }\end{array}$ & $\begin{array}{l}\text { - In to Out errors } \\
\text { and Out to In } \\
\text { errors } \\
\text { - Much } \\
\text { dependency } \\
\text { anchor on } \\
\text { density }\end{array}$ \\
\hline 7. & $\begin{array}{l}\text { Improvement on APIT } \\
\text { Localization } \\
\text { Algorithms for Wireless } \\
\text { Sensor Networks- J } \\
\text { zeng Wang and Hongxu } \\
\text { Jin }\end{array}$ & $\begin{array}{l}\text { Improvement } \text { in } \\
\text { APIT by using } \\
\text { backtracking }\end{array}$ & $\begin{array}{l}\text { - Probability of In } \\
\text { to Out error and } \\
\text { Out to In error } \\
\text { reduced. } \\
\text { - Backtracking } \\
\text { enhanced the } \\
\text { accuracy of } \\
\text { positioning }\end{array}$ & $\begin{array}{l}\text { - Need neighbor } \\
\text { density above } 8 \text {. }\end{array}$ \\
\hline 8. & $\begin{array}{l}\text { On improving APIT } \\
\text { algorithm for better } \\
\text { localization in WSN-. } \\
\text { M. Hosseinirad , M. } \\
\text { Niazi, J. Pourdeilami, S. } \\
\text { K. Basu1, and A. A. } \\
\text { Pouyan }\end{array}$ & $\begin{array}{l}\text { Modified APIT by } \\
\text { segmenting } \\
\text { application area into } \\
\text { sub regions }\end{array}$ & $\begin{array}{l}\text { - Avoided } \\
\text { useless anchor } \\
\text { selection } \\
\text { - Reduced } \\
\text { computational } \\
\text { overhead } \\
\text { - Increased } \\
\text { accuracy }\end{array}$ & $\begin{array}{l}\text { - } 5 \text { to } 10 \text { anchors } \\
\text { required in each } \\
\text { sub region }\end{array}$ \\
\hline 9. & $\begin{array}{l}\text { Localization from mere } \\
\text { connectivity in sensor } \\
\text { networks- Y.Shang, W. } \\
\text { Ruml, Y. Zhang, and } \\
\text { M. Fromherz. }\end{array}$ & 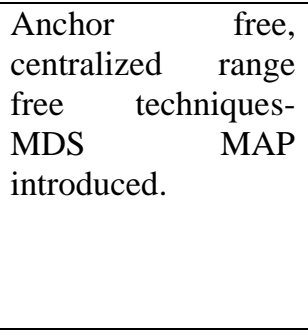 & $\begin{array}{l}\text { - Performs well } \\
\text { in regular layout } \\
\text { of networks } \\
\text { - More robust to } \\
\text { measurement } \\
\text { error than } \\
\text { previous } \\
\text { proposals }\end{array}$ & $\begin{array}{l}\text { - Limited utility } \\
\text { due to centralized } \\
\text { fashion } \\
\text { - Can't give good } \\
\text { results in irregular } \\
\text { shaped networks }\end{array}$ \\
\hline 10 . & $\begin{array}{l}\text { Improved MDS-based } \\
\text { localization-Y.Shang } \\
\text { and W.Ruml }\end{array}$ & $\begin{array}{l}\text { Distributed MDS- } \\
\text { MAP }(P) \text { introduced }\end{array}$ & $\begin{array}{l}\text { - Works well in } \\
\text { both uniform and } \\
\text { irregular networks }\end{array}$ & $\begin{array}{l}\text { - Improved results } \\
\text { at the cost of } \\
\text { additional } \\
\text { computation } \\
\text { overhead }\end{array}$ \\
\hline
\end{tabular}




\begin{tabular}{|c|c|c|c|c|}
\hline 11. & $\begin{array}{l}\text { A New Distributed } \\
\text { weighted } \\
\text { Multidimensional } \\
\text { scaling Algorithm for } \\
\text { Localization } \\
\text { Wireless in } \\
\text { Networks- Fahimeh } \\
\text { Doremami,Dr. Hamid } \\
\text { Haj Seyyed Javadi and } \\
\text { Dr. Ahmad Farahi }\end{array}$ & $\begin{array}{l}\text { New Distributed } \\
\text { weighted } \\
\text { multidimensional } \\
\text { scaling (dwMDS) } \\
\text { Algorithm } \\
\text { introduced }\end{array}$ & $\begin{array}{l}\text { - Reduced } \\
\text { computation cost, } \\
\text { convergence time } \\
\text { and complexity of } \\
\text { calculations }\end{array}$ & $\begin{array}{ll}\text { - Sufficient } & \\
\text { anchors } & \text { are } \\
\text { required } & \text { for } \\
\text { satisfactory } & \\
\text { accurate results } & \end{array}$ \\
\hline
\end{tabular}

\section{Open Issues}

Many improvements have been done in the range free localization techniques to increase their efficiency so that they can be implemented in wide range of application areas. But many issues are still left to be dealt with. In this section open issues are raised to provide future directions of research.

5.1. Efficient Algorithm for Mobile Sensor Networks: Recently, research has been done on implementing mobility in sensor networks to increase the efficiency of initial deployment of sensor nodes. A robust localization scheme is required to accommodate these moving nodes.

5.2. Considering the Minimum Number of Anchor Nodes: Node self localization depends on a set of anchor nodes. But they increase the cost of network. So, an optimal as well as robust scheme needs to be developed that have a minimum number of anchor nodes in a region. Further work is needed to find the minimum number of locations where these anchors must be placed so that the whole network can be localized with a desired level of accuracy.

5.3. Security and Privacy: WSNs are of great use in military purposes because of their size and ease in implementation. Localization is fundamental key to be considered for this. So, reliable location estimation should be provided by localization techniques to ensure security.

5.4. An All Application Localization Technique: Currently available localization techniques work efficiently in specific environments and situations. But, none of the available techniques is best suited to all applications of WSN. So, research should be done to develop an all application localization technique.

\section{Conclusion}

Localization in wireless sensor network is a current area of research. Range free localization techniques have proven to be superior than range based techniques by their satisfactory performance even under the constraints of low size, cost and energy consumption of WSN. This work provides a comprehensive survey of significant research done in range free localization. Subsequently, a summary of qualitative evaluation of important range free localization techniques and their improved versions is presented by highlighting their pros and cons. Open issues have been raised that will prove to be a great help for upcoming researchers in this field. 


\section{Acknowledgments}

We would like to express gratitude to the teachers of Guru Nanak Dev University, Regional Campus, Jalandhar, Punjab for their technical and logistic support. Also we are thankful to almighty without whom this would not be possible.

\section{References}

[1] D. Chen, W. Wang, Y. Zhou."An Improved DV-Hop Localization Algorithm in Wireless Sensor Networks"-, International Conference on Computer and Communication Technologies in Agriculture Engineering,Chengdu. (2010) June 12-13. pp. 266-269.

[2] W. Dargie and C. Poellabauer, "Fundamentals of wireless sensor networks, theory and practice", A John Wiley \& Sons, USA, (2010), pp. 249-266.

[3] J. Wang and H. Jin, "Improvement on APIT Localization Algorithms for Wireless Sensor Networks", IEEE international Conference on Network Security, Wireless Communications and Trusted Computing, Wuhan, Hubei, (2009) April 25-26, pp. 719-723.

[4] D. Niculescu and B. Nath, "DV Based Positioning in Ad Hoc Networks", Telecommunication Systems, vol. 22, no. 1-4, (2003), pp. 267-280.

[5] J. Zheng and A. Jamalipour, "Wireless sensor Networks- A networking perspective", A John Wiley \& Sons, Hoboken, New Jersey, USA, (2009), pp. 276-313.

[6] X. Su and Z. Lei, "Improved Centroid Algorithm Localization for WSN Based on Particle Swarm Optimization”, 2011 Fourth International Symposium on Computational Intelligence and Design, Hangzhou, vol. 1, no. 28-30, (2011) October, pp. 139-142.

[7] T. He, C. Huang, B. M. Blum, J. A. Stankovic and T. Abdelzaher, "Range-free localization schemes for large scale sensor networks", Proceedings of the 9th ACM Annual International Conference on Mobile Computing and Networking (MobiCom'03), (2003) September, pp. 81-95.

[8] R. Stoleru, T. He and J. A. Stankovic, "Secure Localization and Time Synchronization for Wireless Sensors and Ad Hoc Networks", Springer US, USA, (2007), pp. 3-31.

[9] D. Niculescu and B. Nath, "Ad-hoc positioning system", Proceedings of the Global Telecommunications Conference, San Antonio, (2001) November 25-29, pp. 2926- 2931.

[10] F. Doremami, Dr. H. Haj Seyyed Javadi and Dr. A. Farahi, "A New Distributed weighted Multidimensional scaling Algorithm for Localization in Wireless Sensor Networks", International Journal of Computer Science \& Engineering Survey(IJCSES), vol. 2, no. 1, (2011) February.

[11] Y. Shang, W. Ruml, Y. Zhang and M. Fromherz, "Localization from mere connectivity", ACM MobiHoc, Annapolis, MD, (2003) June, pp. 201-212.

[12] Y. Shang and W. Ruml, "Improved MDS-Based Localization", Proceedings of IEEE Infocom, Hong Kong, China, (2000) March, pp. 2640-2651.

[13] J. Xiang and W. Wei Tan, "An Improved DV-hop Algorithm Based on Iterative Computation for Wireless Sensor Network Localization", IEEE International workshop on electromagnetics, Kowloon, (2013) August 1-3.

[14] N. Bulusu, J. Heidemann and D. Estrin. "GPS-less low-cost outdoor localization for very small devices", IEEE Personal Communications, vol. 7, (2000), pp. 28-34.

[15] S. M. Hosseinirad, M. Niazi, J. Pourdeilami, S. K. Basu1 and A. A. Pouyan, "On improving APIT algorithm for better localization in WSN", Journal of AI and Data Mining, vol. 2, no. 2, (2014), pp. 97104.

[16] J. Yick, B.Mukherjee and D. Ghosal, "Wireless sensor network survey", Computer Networks, vol. 52, no. 12 , (2008), pp. 2292-2330.

[17] X. Li, J. Branke and T. Blackwell, "Particle swarm with speciation and adaptation in a dynamic environment", GECCO'06: Proceedings of the 8th annual Conference on Genetic and Evolutionary Computation, ACM Press, New York, NY, USA, (2006), pp. 51-58.

[18] T. S. Rappapport, "Wireless Communications: Principles and Practice", Prentice Hall: New Jersey, IEEE Press, (1996), pp. 50-143.

[19] N. Patwari, J. N. Ash, S. Kyperountas, A. O. Hero III, R. L. Moses and N. S. Correal, "Locating the nodes", IEEE Signal Processing Magazine, (2005) July.

[20] T. Hornoch, "Notes on the Adjustment of Trilateration", Survey Review, vol. 18, no. 135, (1965), pp. 14-18.

\section{Authors}

Er. Ravneet Kaur received B.Tech. degree in Electronics and Communication from DAV Institute of Engineering and Technology, Jalandhar in 2014 and is pursuing 
M.Tech. in ECE (Specialization in Communication Systems) from GNDU, Regional Campus, Jalandhar. Her research area includes localization in WSN.

Dr. Jyoteesh Malhotra B.Eng., M.Tech., PhD. is involved in teaching and research at Electronics and Communication Department, Guru Nanak Dev University, Regional Campus, Jalandhar. His research areas of interest include Statistical modeling of Fading Channels, Fading mitigation techniques in Wireless Communication and Optimization of WBAN air interface. Dr. Malhotra has more than 100 research publications and authored 02 books. He is a life member of I.S.T.E. and editorial board member of many International Journals of repute. 